\title{
Chemo-resistant gestational trophoblastic neoplasia: a review of cases at a tertiary cancer centre
}

\author{
Sharayu R. Mirji ${ }^{1 *}$, Shilpa M. Patel ${ }^{1 *}$, Ruchi S. Arora ${ }^{1}$, Ava D. Desai ${ }^{1}$, \\ Meeta H. Mankad ${ }^{1}$, Sangeetha K. ${ }^{1}$, Harsha P. Panchal ${ }^{2}$
}

\begin{abstract}
${ }^{1}$ Department of Gynecologic Oncology, ${ }^{2}$ Department of Medical Oncology, Gujarat Cancer and Research Institute, Ahmedabad, Gujarat, India
\end{abstract}

Received: 07 February 2019

Accepted: 06 March 2019

\section{*Correspondence:}

Dr. Shilpa M. Patel,

E-mail: drshilpamukesh@gmail.com

Copyright: (c) the author(s), publisher and licensee Medip Academy. This is an open-access article distributed under the terms of the Creative Commons Attribution Non-Commercial License, which permits unrestricted non-commercial use, distribution, and reproduction in any medium, provided the original work is properly cited.

\section{ABSTRACT}

Background: Gestational trophoblastic neoplasia (GTN) was earlier a dreaded malignancy with high mortality rates. GTN is now considered to be one of the most curable solid tumours in women with cure rates greater than $90 \%$ even in the presence of metastases. Despite the high chemo sensitivity, treatment failure or drug resistance has been described in both groups.

Methods: In this study, available records of GTN cases over 6 years were reviewed with emphasis on those who were resistant to the first line of chemotherapy. Of these, 37(34.58\%) were resistant to the first line of chemotherapy. These cases were studied with respect to age, parity, antecedent pregnancy, interval from antecedent pregnancy, pretreatment $\beta \mathrm{hCG}$, risk score and presence of metastases. The data was analyzed in order to find any risk factors associated with chemo-resistance.

Results: Total number of cases of GTN was 107. Out of these 107 cases, $63(58.88 \%)$ were low risk and $44(41.12 \%)$ were high risk according to FIGO scoring system. Complete response was achieved with first line chemotherapy in 70 $(65.42 \%)$ patients. The remaining $37(34.57 \%)$ were resistant to first line chemotherapy. In the low risk group, 30 (47.62\%) cases, and in the high-risk group, 7(15.91\%) were resistant to first line of chemotherapy.

Conclusions: Despite the high chemo sensitivity of GTN, resistance to first line chemotherapy may be encountered in up to $40 \%$ of cases. It is important to identify the patients who are at risk to develop resistance, early identification of resistance and change of chemotherapy so as to minimize the exposure of these patients to ineffective chemotherapy.

Keywords: Chemoresistance, Chemotherapy, Gestational trophoblastic neoplasia

\section{INTRODUCTION}

Gestational trophoblastic neoplasia (GTN) was earlier a dreaded malignancy with high mortality rates. This changed in 1956 when Li et al reported the first complete remission using injection methotrexate (MTX) in a patient with metastatic choriocarcinoma. ${ }^{1}$ GTN is now considered to be one of the most curable solid tumours in women with cure rates greater than $90 \%$ even in the presence of metastases. $^{2}$ This is mainly due to the chemosensitivity of this tumor and the availability of a sensitive tumor marker $\beta$ hCG (beta subunit of human chorionic gonadotropin).

The FIGO prognostic scores are used to classify the patients into low risk (score 0-6) and high-risk groups (score $\geq 7$ ). Despite the high chemo sensitivity, treatment failure or drug resistance has been described in both groups. According to a recent Cochrane systematic 
review, resistance to first line chemotherapy is seen in about $45 \%$ of women with low risk GTN and 30\%-40\% of those with high risk GTN. ${ }^{3}$ A multi-modality approach with multiple lines of chemotherapy, surgical intervention or radiation may sometimes be required. Treatment of patients who develop drug resistance remains a key challenge.

In this study, available records of GTN cases over 6 years were reviewed with emphasis on those who were resistant to the first line of chemotherapy.

\section{METHODS}

This is an observational retrospective study. A total of 107 cases of GTN managed at our regional cancer centre from 2009 till 2016 were reviewed. Of these, 37 $(34.58 \%)$ were resistant to the first line of chemotherapy. These patients required second or third line of chemotherapy, some also required surgical intervention.

\section{Inclusion criteria}

- Cases of GTN which failed to achieve remission with first line of chemotherapy with either a plateau of $\beta$ hCG.

- $\quad$ Rising $\beta$ hCG or an inadequate log fall and required second or third line of chemotherapy or surgical intervention.

\section{Exclusion criteria}

- Those patients who went into remission with the first line of chemotherapy and did not require any further treatment with no relapse.

The cases files were studied with respect to age, parity, antecedent pregnancy, interval from antecedent pregnancy, pre-treatment $\beta \mathrm{hCG}$, risk score and presence of metastases. Follow up visits were tracked to note any case of relapse.

The data was analysed in order to find any risk factors associated with chemo-resistance. All the cases were put on surveillance according to protocol. Patients were followed till December 2018.

\section{RESULTS}

Total number of cases of GTN was 107. Out of these 107 cases, $63(58.88 \%)$ were low risk and 44 (41.12\%) were high risk according to FIGO scoring system. Complete response was achieved with first line chemotherapy in 70 $(65.42 \%)$ patients.

The remaining $37(34.57 \%)$ were resistant to first line chemotherapy. In the low risk group, 30 (47.62\%) cases, and in the high-risk group, $7(15.91 \%)$ were resistant to first line of chemotherapy as shown in Table 1.
Table 1: Number of resistant cases of the total GTN patients (total number $\mathbf{n}=107$ ).

\begin{tabular}{|l|l|l|l|l|}
\hline & No. of cases & $\%$ & $\begin{array}{l}\text { Resistant } \\
\text { cases }\end{array}$ & $\%$ \\
\hline Low risk & 63 & 58.88 & 30 & 47.62 \\
\hline High risk & 44 & 41.12 & 7 & 15.91 \\
\hline Total & 107 & & & 34.58 \\
\hline
\end{tabular}

The mean age of patients was 27.64 years (19 to 47 years). The mean pre-treatment $\beta$-hCG was $1,93,006$ IU/L (113- 12,00,000 IU/L). The mean follow up duration was 17.04 months. Antecedent pregnancy was vesicular mole in more than half of the patients $(53.85 \%)$. The history of antecedent pregnancy is shown in Table 2.

Table 2: Antecedent pregnancy in the two groups $(n=107)$.

\begin{tabular}{|l|l|l|l|}
\hline $\begin{array}{l}\text { Antecedent } \\
\text { pregnancy }\end{array}$ & Responders & $\begin{array}{l}\text { Non- } \\
\text { responders }\end{array}$ & Total \\
\hline Vesicular mole & 36 & 20 & 56 \\
\hline Abortion & 18 & 14 & 32 \\
\hline Term pregnancy & 16 & 3 & 19 \\
\hline Total & 70 & 37 & 107 \\
\hline
\end{tabular}

The mean interval between the antecedent pregnancy and diagnosis of GTN was 8.37 months. Of the total 107 patients, $36(33.64 \%)$ had metastases. Metastases in the two groups are shown in table 3. (Responders- responded to first line chemotherapy; non-responders- resistant to first line chemotherapy).

Table 3: Site of metastasis $(n=36)$.

\begin{tabular}{|l|l|l|l|}
\hline Site of metastasis & Responders & $\begin{array}{l}\text { Non- } \\
\text { responders }\end{array}$ & Total \\
\hline Only lung & 17 & 9 & 26 \\
\hline Vagina & 1 & 1 & 2 \\
\hline $\begin{array}{l}\text { Lungs and vagina } \\
\text { Lungs and liver }\end{array}$ & 5 & 0 & 5 \\
\hline Lungs and brain & 1 & 1 & 1 \\
\hline $\begin{array}{l}\text { Vagina, lungs, } \\
\text { liver, brain }\end{array}$ & 1 & 0 & 1 \\
\hline Total & 25 & 0 & 1 \\
\hline
\end{tabular}

All low risk patients (63) received methotrexate/folinic acid (MTX/FA) initially. Thirty of these did not respond adequately, with plateauing of $\beta$ hCG in 17 and rising $\beta$ hCG in 13 patients. Of these 30 cases, 20 were given actinomycin D (Act D) as second line chemotherapy. Eight responded and achieved remission with Act D. The remaining 12 patients did not have an adequate log fall with multiple cycles of Act D and were given etoposide, methotrexate, actinomycin D, cyclophosphamide, vincristine (EMA CO) as the third line chemotherapy. Eleven achieved remission with EMA CO and are on surveillance. One patient who was started on EMA CO, 
had severe gastrointestinal toxicity and grade IV neutropenia. She succumbed after the first cycle.

Ten patients were given EMA CO directly after MTX. Of these, 8 achieved remission and are on follow up. One patient had plateauing of $\beta$ hCG and was given etoposide, methotrexate, actinomycin D, etoposide, cisplatin (EMA EP), she achieved remission after 2 cycles of EMA EP. One patient was lost to follow up. One non-metastatic low risk case, started on MTX, took irregular treatment and developed resistant disease with pulmonary metastasis. She received multiple lines of chemotherapy and surgical intervention in the form of total hysterectomy and pulmonary resection. She did not achieve remission. All high-risk patients (44) received EMA CO as initial treatment. Seven of them did not show adequate response to first line chemotherapy, with rise in $\beta$ hCG in 3 and plateauing in 4 patients. Two were given bleomycin, etoposide, cisplatin (BEP) as second line and both achieved remission after 2 cycles and are on surveillance. Two were given EMA EP, one achieved remission while the other was lost to follow up.

In two patients, after receiving 7 and 8 cycles of EMA $\mathrm{CO}$, there was plateauing and rise in $\beta$ hCG. A repeat metastatic workup revealed disease limited to the uterus. Abdominal hysterectomy was done in both following which there was an immediate fall in $\beta$ hCG. Both of them achieved remission after two more cycles of EMA CO. One patient who was resistant to multiple lines of chemotherapy underwent surgical interventionhysterectomy and pulmonary resection and is in remission. The patients who required multiple lines of chemotherapy were further studied to find any factors responsible for the initial chemo-resistance. Authors found a high rate of chemo-resistance in our low risk group- $47.62 \%$. The characteristics of the low risk chemo-resistant patients were analysed. Table 4 shows the pre-treatment $\beta$ hCG levels in the low risk chemoresistant group.

Table 4: Pre-treatment $\beta$ hCG level in low risk chemoresistant cases $(n=30)$.

\begin{tabular}{|l|l|}
\hline$\beta$ hCG (IU/L) & Number of patients \\
\hline$<1000$ & None \\
\hline $1000-<10,000$ & 6 \\
\hline $10,000-<1,00,000$ & 19 \\
\hline$\geq 1,00,000$ & 5 \\
\hline
\end{tabular}

Table 5: Risk scores in low risk chemo-resistant cases $(\mathbf{n}=30)$.

\begin{tabular}{|l|l|}
\hline Risk score & Number of patients \\
\hline 2 & 9 \\
\hline 3 & 9 \\
\hline 4 & 2 \\
\hline 5 & 4 \\
\hline 6 & 6 \\
\hline
\end{tabular}

All low risk chemo-resistant cases had $\beta$ hCG more than $1000 \mathrm{IU} / \mathrm{L}$ and in $24(80 \%)$ patients, it was more than 10,000 IU/L.The FIGO risk scores of low risk chemoresistant cases are shown in Table 5.

Thus, ten patients had a risk score of 5 or 6 (corresponding to intermediate risk group of earlier classification). History of antecedent pregnancy in the low risk chemo-resistant patients is shown in Table 6.

Table 6: Antecedent pregnancy in low risk chemoresistant cases $(n=30)$.

\begin{tabular}{|l|l|}
\hline Antecedent pregnancy & Number \\
\hline Vesicular mole & 18 \\
\hline Abortion & 11 \\
\hline Term pregnancy & 1 \\
\hline
\end{tabular}

Metastases in low risk chemo-resistant patients is shown Table 7.

Table 7: Metastases in low risk chemo-resistant cases $(n=30)$.

\begin{tabular}{|l|l|}
\hline Site of metastases & Number \\
\hline Lungs & 6 \\
\hline Vagina & 1 \\
\hline None & 23 \\
\hline
\end{tabular}

The age of patients in the low risk chemo-resistant group is shown in Table 8 .

Table 8: Age in low risk chemo-resistant cases $(n=30)$.

\begin{tabular}{|l|l|}
\hline Age & Number of patients \\
\hline$<20-24$ & 14 \\
\hline $25-30$ & 13 \\
\hline$>30$ & 3 \\
\hline
\end{tabular}

The risk factors present in the low risk chemo-resistant patients are shown in Table 9. Resistance to initial chemotherapy may be attributed to one or more of these.

Table 9: Risk factors in low risk chemo-resistant patients $(n=30)$.

\begin{tabular}{|l|l|}
\hline Risk factor & No. of patients \\
\hline Intermediate risk score (5 and 6) & 10 \\
\hline Scores 2, 3 and 4 & 20 \\
\hline$\beta$ hCG $>10,000$ & 8 \\
\hline Metastases (lungs and vagina) & 4 \\
\hline Age >30 years & 3 \\
\hline Previous incomplete treatment & 2 \\
\hline No other risk factors & 3 \\
\hline
\end{tabular}

Of the 30 low risk patients who were resistant to first line chemotherapy (MTX/FA), 27 (90\%) had some high-risk factor, 10 had risk scores 5 or 6 (intermediate risk), 4 patients had metastases (lungs and vagina), 8 had high 
pre-treatment $\beta$ hCG $(>10,000)$. In 6 of these, it was more than 50,000 IU/L. Three patients were around 35 years old (34, 36 and 37). Two patients had received incomplete treatment outside and were then referred. Clinical and biochemical features of high risk GTN patients resistant to initial chemotherapy are shown in Table 10.

Table 10: Characteristics of patients with high risk chemo-resistant GTN (n=7).

\begin{tabular}{|c|c|c|}
\hline \multicolumn{2}{|l|}{ Risk factor } & $\begin{array}{l}\text { No. of } \\
\text { patients }\end{array}$ \\
\hline \multirow{4}{*}{$\begin{array}{l}\text { Pre-treatment } \beta \\
\text { hCG }(\mathrm{IU} / \mathrm{L})\end{array}$} & $<1,00,000$ & 1 \\
\hline & $1,00,000-5,00,000$ & 3 \\
\hline & $5,00,000-10,00,000$ & 2 \\
\hline & $>10,00,000$ & 1 \\
\hline \multirow{3}{*}{$\begin{array}{l}\text { Antecedant } \\
\text { pregnancy }\end{array}$} & Vesicular mole & 1 \\
\hline & Abortion & 5 \\
\hline & Term pregnancy & 1 \\
\hline \multirow{5}{*}{ FIGO score } & 8 & 2 \\
\hline & 9 & 1 \\
\hline & 10 & 1 \\
\hline & 11 & 1 \\
\hline & 12 & 2 \\
\hline \multirow{2}{*}{ Site of metastases } & Lung & 6 \\
\hline & Lung + liver & 1 \\
\hline
\end{tabular}

Characteristics of high-risk chemo-resistant cases as shown in table 10 -all patients had $\beta$ hCG $>1,00,000 \mathrm{IU} / \mathrm{L}$. All had pulmonary metastases, one patient had pulmonary and hepatic metastases. Two patients had FIGO risk score of 8 , in others it was more than 9 .

\section{DISCUSSION}

GTN is highly responsive to chemotherapy. The cure rate of low risk cases approaches $100 \%$ and that of high-risk cases is more than $90 \% .^{2}$ Despite the high chemo sensitivity, resistance to first line chemotherapy is sometimes encountered, requiring second or third line salvage chemotherapy. In some cases, surgical excision of isolated chemo-resistant disease may be required.

According to a recent Cochrane systematic review, resistance to first line chemotherapy is seen in about $45 \%$ of women with low risk GTN and $30 \%-40 \%$ of those with high risk GTN. ${ }^{3}$

In present study, resistance to initial chemotherapy was seen in $37(34.58 \%)$ patients. MTX/FA was the initial chemotherapy in all low risk patients and resistance was seen in $47.62 \%$. All high-risk patients were initially treated with EMA CO and resistance was seen in $15.91 \%$ of cases.

More than half cases $(52.34 \%)$ had antecedent vesicular mole. This is also seen in majority of the studies.,5
Metastases were present in $33.64 \%$ of cases and the most common site was lungs (72.22\%).

\section{Low risk GTN}

Resistance to first-line chemotherapy has been reported in up to $45 \%$ of women with low-risk GTN, depending on the regimen used. ${ }^{3,6}$ Hemida et al reported resistance to first line chemotherapy (MTX) in $15.15 \%$ of low risk cases. ${ }^{4}$ In another study by Mousavi et al, resistance to first line single agent chemotherapy was reported in $43 \%$ of low risk patients. ${ }^{7}$ In present study, similar results were obtained and resistance to first line chemotherapy was seen in $47.62 \%$ of low risk cases.

Risk factors for drug resistance in low risk GTN include a high pre-treatment $\beta$ hCG $(>1,00,000$ IU/ L), intermediate risk scores ( 5 or 6 ), non-molar antecedent pregnancy and a histological diagnosis of choriocarcinoma. $^{3,6,8,9,10}$ A study from Charring Cross hospital concluded that the cure rate with single agent chemotherapy (MTX) in low risk GTN with $\beta$ hCG level $>1,00,000 \mathrm{IU} / \mathrm{L}$ was only $30 \%$ and it was much lower in those with higher levels. ${ }^{8}$ Drug resistance to primary chemotherapy is also associated with higher relapse rates. $^{11}$

In present study, among the resistant low risk cases, one or the other risk factors (FIGO score 5 or $6, \beta$ hCG $>10,000$, metastases, age $>30$ years and previous incomplete treatment) was present in $90 \%$ as given in Table 9. Ten patients had risk scores 5 or 6 (intermediate risk). Mousavi et al reported that the resistance to first line chemotherapy was $11 \%$ in those with a score of $<4$, while it was $63 \%$ in those with score $\geq 4$, which was 14 fold higher. ${ }^{7}$

Seckl et al, reported only $30 \%$ of intermediate risk score patients can be expected to be cured with first line chemotherapy. ${ }^{12}$ ESMO (European society of medical oncology) guidelines suggest a refinement of the FIGO scoring system so that $70 \%$ of women in intermediate risk group who develop resistance to MTX/FA, could be identified initially for more intensive therapy. ${ }^{13}$

In present study methotrexate/ folinic acid (MTX/FA) regimen was used as the first line chemotherapy in all low risk patients. The MTX/FA regimen is effective, well tolerated, does not induce hair loss and in most cases can be taken even from a general practitioner.

Hence MTX/FA is most widely accepted as the first line drug. ${ }^{14}$ After resistance to first line chemotherapy either a second line single agent therapy or a multi agent regimen is given.

Multi agent chemotherapy is indicated in case of significant elevation of $\beta \mathrm{hCG}$, development of metastases or resistance to sequential single agent chemotherapy. $^{2}$ 
In spite of risk factors, chemo-resistance and use of multiple modalities of treatment, the salvage rate in low risk GTN approaches $100 \% .^{2,7}$

\section{High risk GTN}

High risk patients are treated more aggressively with multi agent chemotherapy with or without radiation or surgery. EMA/ CO is the most widely used primary combination therapy. However, it has been reported that about $30 \%$ to $40 \%$ of women will develop resistance or will relapse after remission and need salvage chemotherapy. ${ }^{3,15}$ In present study, resistance was seen in 7 patients that is in $15.91 \%$ of high-risk cases. Hemida et al reported resistance in $60 \%$ high risk patients. However, they had MAC regimen as first line therapy and their study population was small. ${ }^{4} \mathrm{Ngu}$ et al reported resistance in $25 \%$ of high risk cases. ${ }^{16}$ The various salvage regimens used are EMA EP, BEP, EP, VBP (vinblastine, bleomycin, cisplatin), VIP (vinblastine, ifosfamide, cisplatin) among others. Salvage chemotherapy with the EMA-EP regimen is most widely used. This regimen is highly toxic and usually requires granulocyte colony stimulating factor support by the third cycle. ${ }^{17}$

Risk factors for resistance to treatment in high-risk GTN include high FIGO score, the number and sites of metastases, incomplete previous treatments, and the stage of the tumour..$^{3,18}$ Metastases to brain, liver, gastrointestinal tract are associated with worse prognosis. ${ }^{3,19}$ In present study 6 of the 7 high risk chemoresistant patients had score of $\geq 9$. All patients had pulmonary metastasis and one patient had hepatic metastasis. All except one had a pre-treatment $\beta$ hCG above 1,00,000 IU/L (Table 10). Two patients, after 7 and 8 cycles of EMA CO had rise in $\beta$ hCG. A repeat metastatic work up revealed disease limited to the uterus. Total hysterectomy was done in both patients, after which there was a fall in $\beta$ hCG. Both achieved remission after two more cycles of EMA CO and are on surveillance. One patient achieved remission after multiple lines of chemotherapy as well as surgical intervention in the form of total hysterectomy and pulmonary resection. Salvage therapy is more likely to fail in heavily pre-treated patients. ${ }^{20}$

\section{CONCLUSION}

Despite the high chemo sensitivity of GTN, resistance to first line chemotherapy may be encountered in up to $40 \%$ of cases. However, most patients achieve cure with salvage treatment. It is important to identify the patients who are at risk to develop resistance, early identification of resistance and change of chemotherapy so as to minimize the exposure of these patients to ineffective chemotherapy. All GTN patients must be managed at tertiary care centres with a multidisciplinary team approach. Individualization of treatment is most important while managing such chemo-resistant cases. Several salvage chemotherapeutic regimens are used for treating resistant or recurrent GTN. It is important to identify those regimens which are most effective and least toxic. Future clinical trials and cost-effectiveness studies are needed to determine a better choice of treatment in the intermediate risk group (FIGO score 5-6 - old WHO prognostic scoring system).

\section{Funding: No funding sources \\ Conflict of interest: None declared \\ Ethical approval: Not required}

\section{REFERENCES}

1. LiM C, Hertz R, Spencer DB .Effect of methotrexate therapy upon choriocarcinoma and chorioadenoma. Proc Soc Exp Biol Med. 1956;93(2):361-6.

2. Schink JC, Lurain III JR. Gestational trophoblastic disease: molar pregnancy and gestational trophoblastic Neoplasia. InPrinciples and Practice of Gynecologic Oncology: Sixth Edition 2013. Wolters Kluwer Health pp. 886-908.

3. Alazzam M1, Tidy J, Osborne R, Coleman R, Hancock BW, Lawrie TA, Chemotherapy for resistant or recurrent gestational trophoblastic neoplasia. Cochrane Database Syst Rev. 2012;12:CD008891.

4. Hemida RA, Toson E, Shalaby H, Refaie E, Eldin DS. Chemo-resistant gestational trophoblastic neoplasia, 5-years' experience of Mansoura University Hospital, Egypt. Open J Obstet Gynecol. 2011;1(03):153.

5. Kuyumcuoglu U, Guzel AI, Erdemoglu M, Celik Y. Risk factors for persistent gestational trophoblastic neoplasia. J Experiment Therapeut Oncol. 2011;9(1):81-4.

6. Osborne RJ, Filiaci V, Schink JC, Mannel RS, Alvarez Secord A, Kelley JL, et al. Phase III trial of weekly methotrexate or pulsed dactinomycin for low-risk gestational trophoblastic neoplasia: a Gynecologic Oncology Group study. J Clinic Oncol. 2011;29(7):825-31.

7. Mousavi AS, Zamani A, Khorasanizadeh F, Gilani MM, Zendehdel K. Resistance to single-agent chemotherapy and its risk factors in low-risk gestational trophoblastic neoplasms. J Obstet Gynaecol Res. 2015;41(5):776-83.

8. McGrath S, Short D, Harvey R, Schmid P, Savage PM, Seckl MJ. The management and outcome of women with post-hydatidiform mole 'low-risk' gestational trophoblastic neoplasia, but hCG levels in excess of $100 \quad 000$ IU/L Brit J Cancer 2010;102(5):810-4.

9. El-Helw LM, Coleman RE, Everard JE, Tidy JA, Horsman JM, Elkhenini HF, et al. Impact of the revised FIGO/WHO system on the management of patients with gestational trophoblastic neoplasia. Gynecol Oncol 2009;113(3):306-11.

10. Lurain JR, Elfstrand EP. Single-agent methotrexate chemotherapy for the treatment of nonmetastatic 
gestational trophoblastic tumors. Am J Obstet Gynecol. 1995;172(2):574-9.

11. Matsui H, Suzuka K, Yamazawa K, Tanaka N, Mitsuhashi A, Seki K, et al. Relapse rate of patients with low-risk gestational trophoblastic tumor initially treated with single-agent chemotherapy. Gynecol Oncol. 2005;96(3):616-20.

12. Seckl MJ, Sebire NJ, Berkowitz RS. Gestational trophoblastic disease. The Lancet. 2010;376(9742):717-29.

13. Seckl MJ, Sebire NJ, Fisher RA, Golfier F, Massuger L, Sessa C, ESMO Guidelines Working Group. Gestational trophoblastic disease: ESMO Clinical Practice Guidelines for diagnosis, treatment and follow-up. Annals Oncol. 2013;24(6):vi39-50.

14. McNeish IA, Strickland S, Holden L, Rustin GJ, Foskett M, Seckl MJ, Newlands ES. Low-risk persistent gestational trophoblastic disease: outcome after initial treatment with low-dose methotrexate and folinic acid from 1992 to 2000. J Clinic Oncol. 2002;20(7):1838-44.

15. Goldstein DP, Berkowitz RS. Current management of gestational trophoblastic neoplasia. Hematol Oncol Clinic North America 2012;26(1):111-31.

16. Siew-FeiNgu, Karen K. L. ChanManagement of Chemoresistant and Quiescent Gestational Trophoblastic Disease. Curr Obstet Gynecol Rep. 2014;3(1):84-90.

17. Newlands ES, Mulholand PJ, Holden L, et al. Etoposide and cisplatin/etoposide, methotrexate, and actinomycin D (EMA) chemotherapy for patients with high-risk gestational trophoblastic tumors refractory to EMA/cyclophosphamide and vincristine chemotherapy and patients presenting with metastatic placental site trophoblastic tumors. J Clin Oncol. 2000;18(4):854-859.

18. Wang J, Short D, Sebire NJ, Lindsay I, Newlands ES, Schmid $P$ et al. Salvage chemotherapy of relapsed or high-risk gestational trophoblastic neoplasia (GTN) with paclitaxel/cisplatin alternating with paclitaxel/etoposide (TP/TE). Ann Oncol.2008;19(9):1578-83.

19. Lurain JR, Schink JC. Importance of salvage therapy in the management of high-risk gestational trophoblastic neoplasia. J Reprod Med. 2012;57(5-6):219-24.

20. Feng F, Xiang Y, Wan X, Geng S, Wang T. Salvage combination chemotherapy with floxuridine, dactinomycin, etoposide, and vincristine (FAEV) for patients with relapsed/chemoresistant gestational trophoblastic neoplasia. Ann Oncol. 2011;22(7):1588-94.

Cite this article as: Mirji SR, Patel SM, Arora RS, Desai AD, Mankad MH, Sangeetha K, et al. Chemoresistant gestational trophoblastic neoplasia: a review of cases at a tertiary cancer centre. Int J Reprod Contracept Obstet Gynecol 2019;8:1620-5. 